Article

\title{
Bridge over Troubled Water: Linking Capacities of Sport and Non-Sport Organizations
}

\author{
Mathieu Marlier ${ }^{1,2, *}$, Bram Constandt ${ }^{2}$, Cleo Schyvinck ${ }^{2}$, Thomas De Bock ${ }^{2}$, Mathieu Winand ${ }^{1}$ \\ and Annick Willem ${ }^{2}$ \\ ${ }^{1}$ Department of International Sport Management, LUNEX International University of Health, Exercise, and Sports, \\ 4671 Differdange, Luxembourg; E-Mails: mathieu.marlier@lunex-university.net (M.M.), \\ mathieu.winand@lunex-university.net (M.W.) \\ 2 Department of Movement and Sport Sciences, Ghent University, 9000 Gent, Belgium; \\ E-Mails: mathieu.marlier@ugent.be (M.M.), bram.constandt@ugent.be (B.C.), cleo.schyvinck@ugent.be (C.S.), \\ thomas.debock@ugent.be (T.D.B.), annick.willem@ugent.be (A.W.) \\ * Corresponding author
}

Submitted: 31 December 2019 | Accepted: 23 March 2020 | Published: 17 August 2020

\begin{abstract}
Community Sport Development Programs (CSDPs) that use an intersectoral capacity building approach have shown potential in reaching individuals in disadvantaged situations. This study has investigated how the application of capacity building principles in disadvantaged communities results in higher sport participation rates in these communities. A multiple case design was used, including six similar disadvantaged communities in Antwerp, Belgium; four communities implemented the CSDP, two communities served as control communities without CSDP. In total, 52 face-to-face interviews were held with sport, social, health, cultural, and youth organizations in these communities. Four key findings were crucial to explain the success of the CSDP according to the principles of capacity building. First, the CSDP appeared to be the missing link between sport organizations on the one hand and health, social, youth, and cultural organizations on the other hand. Second, shifting from a sport-oriented staff to a mix of sport staff, social workers and representatives of people in disadvantaged situations helped increase trust through a participatory approach. Third, CSDPs assisted sport clubs to deal with financial, organizational, and cultural pressures that arose from the influx of new members in disadvantaged situations. Finally, the CSDPs developed well-planned and integrated strategies focusing on reinforcing the existing local organizations already using sport to reach their goals. These capacity building principles were key in attaining higher sport participation for people living in disadvantaged communities.
\end{abstract}

\section{Keywords}

capacity building; community sport; disadvantaged communities; intersectoral partnerships; sport participation; youth

\section{Issue}

This article is part of the issue "Sport for Development: Opening Transdisciplinary and Intersectoral Perspectives" edited by Pascal Delheye (Ghent University, Belgium), Kirsten Verkooijen (Wageningen University \& Research, The Netherlands), Dan Parnell (University of Liverpool, UK), John Hayton (Northumbria University, UK) and Reinhard Haudenhuyse (Vrije Universiteit Brussel, Belgium).

(C) 2020 by the authors; licensee Cogitatio (Lisbon, Portugal). This article is licensed under a Creative Commons Attribution 4.0 International License (CC BY).

\section{Introduction}

Enabling as many people as possible to participate in sport is the main target of the public sport sector (Council of Europe, 2001, Articles 1.i and 4.2). Currently, in
Europe, about $40 \%$ of the population engages in weekly sport participation (Scheerder, Vandermeerschen, \& Breedveld, 2017). Unsurprisingly, target groups in disadvantaged situations, such as people from lower social class, and people from cultural ethnic minori- 
ties, engage less in sport than the general population (Vandermeerschen, Vos, \& Scheerder, 2013). Furthermore, the number of ethnic cultural minorities and lower socio-economic groups are growing (Putnam, 2007). Given that Europe will become even more ethnically diverse in the coming years, it is interesting to focus on this relatively unexplored target group from a sport participation point of view. Furthermore, supported by the health discourse in recent years, sport has been used increasingly by many non-sport organizations as a popular means to enhance physical activity levels, social integration, and mental health of people in disadvantaged situations (Marlier et al., 2015). After all, sport is known for its ability to capture or "hook" a large number of people (Schulenkorf, Sherry, \& Rowe, 2016).

Unlike non-sport organizations, many sport organizations (e.g., local sport authorities, sport clubs, sport federations) continue to struggle to include these target groups. Reasons mentioned for this incapacity to engage people in disadvantaged situations are the top down sport promotion initiatives of traditional sport organizations (Lawson, 2005) and the lack of collaboration with partners that have more experience in attracting these target groups (Barnes, Cousens, \& MacLean, 2007). In many sport organizations, these feelings of incapacity result in difficulties to engage with this unknown target group.

The capacity building approach is one promising method to deal with the challenges to engage people in disadvantaged situations and to enhance collaboration (Jones, Edwards, Bocarro, Bunds, \& Smith, 2017). The capacity building approach is based on four principles: (1) valuing pre-existing capacities, (2) developing trust through a participatory approach, (3) being responsive to context, and (4) developing well-planned and integrated strategies with clear purposes (NSW Health Department, 2001). In the sport realm, programs that implement this capacity approach, either explicitly or implicitly, are referred to as Community Sport Development Programs (CSDPs; Hylton, Bramham, Jackson, \& Nesti, 2013). Moreover, these programs are categorized as 'Sport Plus' initiatives because they aim to develop sport participation and developmental goals (e.g., build self-esteem, increase health and social cohesion in the community; see Coalter, 2010). While capacity building has strong historical roots in the health sector, recent studies have also highlighted its usefulness in a sport setting (Edwards, 2015; Jones, Edwards, Bocarro, Svensson, \& Misener, 2019). However, a lack of understanding persists regarding the capacity building processes that explain how to reach individuals in disadvantaged situations through sport. The need to analyze programs that were found effective in engaging disadvantaged individuals through capacity building principles is one of the main issues that hamper these insights (Millar \& Doherty, 2016).

To fill this knowledge gap, this study builds on the results of a previous study that discovered signifi- cant multilevel differences in disadvantaged communities for sport participation between communities with and without CSDP (Marlier, Cardon, De Bourdeaudhuij, \& Willem, 2014). In total, $61.3 \%$ of the participating adults from CSDP-communities reported engagement in sport, whereas in similar control communities without CSDP, this only amounted to 42.4\% (Marlier et al., 2014). Furthermore, populations most at risk of exclusion, such as ethnic women of lower social class, engaged three times more in sport participation than those in the control communities (Marlier et al., 2014). This successful case of a CSDP is used to extract lessons on how (sport) organizations can include individuals in disadvantaged situations. The capacity building principles are used as a theoretical framework to structure these lessons. In summary, this study aims to explain how sport organizations can improve the inclusion of disadvantaged individuals through sport.

In the following sections we focus on the capacity building principles through the framework of the NSW Health Department (2001). This framework has been chosen because of its contribution to the capacity building theory, both from a scholarly as well as a practitioner viewpoint (Heward, Hutchins, \& Keleher, 2007).

\subsection{Capacity Building Principles Underpinning the Delivery of CSDPS}

\subsubsection{Valuing Pre-Existing Capacities}

The first principle of capacity building is valuing preexisting capacities, which refers to the identification and application of skills, experiences, expertise, and resources within the own organization and community, as well as those from other organizations and community members (NSW Health Department, 2001). External partnerships are therefore advocated as a crucial element to overcome capacity deficiencies (Svensson, Hancock, \& Hums, 2017). Nevertheless, the link between the capacities of different organizations is often missing in delivering CSDPs. In one CSDP, where sport trainers were in charge of engaging youth in disadvantaged situations, a lack of capacity to engage this target group was noted (Armour \& Sandford, 2013). In another CSDPs where youth and social workers were responsible for program delivery, staff was confronted with a lack of adequate sport equipment, a deficit of sport pedagogical skills among the supporting staff and limited opportunities to make use of the existing local sport facilities (Theeboom, Haudenhuyse, \& De Knop, 2010). Therefore, a first necessity for successful CSDPs is to bridge this capacity gap by linking and leveraging the capacities of the different sectors.

\subsubsection{Developing Trust through a Participatory Approach}

The second principle is developing trust through a participatory approach (NSW Health Department, 2001). 
This principle concerns the capability to involve the target group in the decision-making process regarding the selection and planning of the activities (Haudenhuyse, Theeboom, \& Nols, 2012; Spaaij, Schulenkorf, Jeanes, \& Oxford, 2018). Such participatory approach in program design, delivery, and evaluation is key in developing trust (Coalter, 2007; Edwards, 2015). One of the success factors of a CSDP (a sport action zone) was to get people from the local community involved in identifying the critical community needs (Sport England, 2006). This involvement also empowered the local people to deal with these community needs by themselves (Sport England, 2006). In another CSDP, aimed at promoting sport participation in tennis, the identification of a community champion (i.e., an ambassador, influencer of the community) was essential for program success (Vail, 2007). One of the key findings in the study was that community champions, in which community members had trust, were much more effective in engaging community members than in communities where trust in such person was lacking (Vail, 2007). Thus, developing trust through a participatory approach is necessary to share skills, knowledge, and resources both for those participating in the activities and for partners collaborating to deliver those activities.

\subsubsection{Being Responsive to Context}

The third principle of capacity building is being responsive to context (NSW Health Department, 2001). This principle refers to the realization that programs do not exist in isolation (Pawson, Greenhalgh, Harvey, \& Walshe, 2005). All programs are influenced by the political, physical, economic, and cultural environments in which they operate. All these factors shape the program for better or for worse (NSW Health Department, 2001). In the context of sport promotion, CSDPs need to be aware of the lack of experience of local sport authorities to engage groups in disadvantaged situations (Vandermeerschen \& Scheerder, 2017). Another important element in the sport promotion context are the sport clubs. In many Western countries these sport clubs are the main actors in sport promotion (Misener \& Doherty, 2012). However, from an organizational perspective, they face many challenges regarding declining volunteer rates, infrastructure deficits and increasingly complex stakeholder demands (Misener \& Doherty, 2012). Coalter (2007) warned that identifying and engaging with hard to reach groups is not the core-activity of sport clubs and that imposing this agenda could be damaging for their sustainability. Taking these specific contextual influences into account will thus partially determine whether a CSDP will be successful or not.

\subsubsection{Developing Well-Planned and Integrated Strategies with Clear Purposes}

The fourth principle of capacity building is developing well-planned and integrated strategies with clear pur- poses to find alternative ways for obtaining sustainability (NSW Health Department, 2001). This means working at the individual, organizational, and partnership levels, with a clear definition of goals, strategies, evaluation, and responsibilities for actions on the different levels (NSW Health Department, 2001; Simmons, Reynolds, \& Swinburn, 2011). For example, in the setting of sport clubs, Allison (2001) claimed that engaging in multiple relationships with organizations across different sectors (e.g., facilities, suppliers, sponsors, media, schools, other clubs, sport councils, and granting agencies) may aid sport clubs to effectively deal with their lack of resources. Furthermore, this engagement also supports the program's sustainability and quality of the sport offer to participants. In 'Street League' - a CSDP that focused on engaging disadvantaged people over sixteen years of age in organized sport and aimed at developing social and other transferable skills in a fun environment-sustainability was achieved through the funding by non-sport focused government agencies and private business (Skinner \& Zakus, 2008). Deciding on the ideal number of organizational strategies and partnerships is difficult. General recommendations are to start small and then to diversify (Welty Peachey, Cohen, Shin, \& Fusaro, 2018).

In light of this background, the current study investigates a case study of a CSDP that was successful in reaching higher sport participation in disadvantaged communities. The aim of the study is to investigate how the capacity building principles help to explain the success of this CSDP.

\section{Method}

\subsection{Description of the CSDP}

The CSDP - the subject of this case study-is situated in Antwerp (506,225 inhabitants, Flanders, Belgium). The program is considered one of the most advanced CSDPs in Flanders (Theeboom \& De Maesschalck, 2006). Since 2003 , this program is structurally organized by the Antwerp Sport Authority (Cas, 2005). The main goal of the CSDP is to increase sport participation opportunities for people in disadvantaged communities, who experience higher financial, mobility, and commitment thresholds to participate in sport or exercise.

In total, 33 full-time equivalent staff members are employed to deliver the CSDP in Antwerp. These employees have five key responsibilities and activities closely related to the capacity building principles (Bogaerts, 2013). Firstly, exchanging information from and to the participating partners (sport, health, social, youth, cultural organizations) in the community, e.g., advising organizations on how to integrate disadvantaged groups into sport and exercise. Secondly, supporting the sport activities of partners, for instance, by personally assisting and guiding people towards existing sport clubs and activities. Furthermore, each partner can ask for (logistical) support of staff members of the CSDP to facilitate the 
organization of their sport activities. Thirdly, organizing sport activities that complement the existing initiatives, or adapting the sport activities to the needs of people in disadvantaged situations (e.g., bike lessons for adults, urban circus for the youngest, street dance for adolescents, street soccer for homeless, walking groups for the elder, and swimming and exercise activities for women only). The fourth responsibility is to create new sport infrastructure in the community (e.g., urban sport infrastructure for skating, parkour, or dancing). Finally, searching for innovative new ways to reach program goals, e.g., organizing a cultural sport festival with local partners where ethnic minorities demonstrate sport from their native country and where community members are invited to try these 'foreign' sports.

At the moment of data collection, 17 of 62 communities located in the city of Antwerp had implemented the CSDP. Three coordinators manage the CSDP at the city level. These coordinators coach and guide 30 staff members delivering the CSDP in the 17 communities, while they also collaborate with the leaders of partner organizations at the city level. In summary, all activities that lower the threshold for people to engage in sport and exercise in their local neighborhood can be considered as part of the CSDP. Hence, communities without a CSDP staff member also have several activities that fit the criteria for the CSDP. The difference is that no staff member will be coordinating and implementing the aforementioned key activities related to the capacity building principles (i.e., exchanging information, supporting partners, organizing complementary sport and movement activities, creating new sport infrastructure, and exploring innovative ways to reach CSDP-goals).

\subsection{Sampling and Data Collection}

A multiple case design was used to assess and explain the capacity building principles that helped to create higher sport participation in disadvantaged communities. Four CSDP-communities and two control communities were purposively selected from the communities that were part of the previous quantitative study (Marlier et al., 2014). We used a qualitative method because this method is the recommended approach to investigate and understand how something works (Yin, 2013). Furthermore, adding multiple cases enabled us to bring more variation and richness to our analysis and make our findings more robust and generalizable (Eisenhardt \& Graebner, 2007; Yin, 2013).

As partnerships are located at the heart of the capacity building theory, sampling of interview participants was done by asking the CSDP staff members whom they considered their most important partner organizations in the sport, health, social, and other sectors. Persons most knowledgeable within the organization were invited to participate in the qualitative case-study. In control communities, potential stakeholders were selected through snowball sampling of organizations that had sport and community-based missions. Three trained researchers visited the participants at their organization and audiorecorded the interviews. Prior to the face-to-face interviews, the interviewees were informed via email about the purpose of the study. All selected participants agreed to participate in the study. This resulted in a total of 52 in-depth, semi-structured interviews, each lasting 40 minutes on average (see Table 1). In the two control communities four interviews per community were executed. In the program communities, the number of interviews ranged from six to ten. Some organizations were active on a city level and thus worked on a supra community level. In total, eleven interviews were conducted at the city level.

Interview questions were developed, based on a review of the literature on successful and effective factors in capacity building (NSW Health Department, 2001). For example, questions were posed like: To what extent does the CSDP make use of the capacity of partner organizations (principle 1: value pre-existing capacities)? To what extent is the target group involved in determining the activities of CSDP (principle 2: build trust through active participation)? Are there environmental influences that hamper or benefit the CSDP and how do you adapt to these (principle 3: be responsive to context)? Is there a joint goal setting and planning in the CSDP (principle 4: plan and integrate clear purposed strategies)?

General questions were also asked regarding the perceptions of the success factors and pitfalls of the CSDP and the added value and experienced problems with the CSDP. The in-depth interviews allowed for probing to deepen the understanding on the processes that helped to understand the success of the CSDP and its partners to reach higher sport participation in disadvantaged communities.

\subsection{Data Analysis}

After transcription of the interviews, qualitative data analysis was conducted with NVivo 12 . Four steps were taken to reduce and analyze the 266,144 words of interview transcripts. Firstly, transcripts were coded following deductive reasoning based on the codebook of underlying principles of capacity building. A selection of the transcripts was coded by a second researcher to test the reliability of coding and to assure the quality of the coding process (Edwards \& Skinner, 2010). Secondly, stakeholder groups were categorized in subsets to isolate comments of sports, social, health, youth, and cultural stakeholders for program and control communities. Thirdly, after the coding-process, recurring patterns of capacity building mechanisms were identified that could explain why CSDPs were able to create higher sport participation in the disadvantaged communities in which they operated. Interviews were conducted and transcribed in Dutch. Quotes used to illustrate and explain certain results were translated from Dutch to English. The reliability of translation of each quote was checked and ver- 
Table 1. Overview of interviewees of different organizations in program communities, control communities and at the city level.

\begin{tabular}{|c|c|c|c|c|c|c|c|c|c|}
\hline & PC 1 & PC 2 & PC 3 & PC 4 & CC 1 & CC 2 & City & Total & Example \\
\hline Staff of CSDP & 2 & 2 & 2 & 2 & / & / & 3 & 11 & \\
\hline $\begin{array}{l}\text { Sport } \\
\text { Organization (SP) }\end{array}$ & 1 & 1 & 3 & 2 & 1 & / & 3 & 11 & $\begin{array}{l}\text { Grassroot sport clubs, local sport } \\
\text { authorities, sport facility administrations }\end{array}$ \\
\hline $\begin{array}{l}\text { Social } \\
\text { Organization (SO) }\end{array}$ & 2 & 3 & 3 & 1 & 2 & 4 & 4 & 19 & $\begin{array}{l}\text { Outreach organizations, organizations } \\
\text { fighting against drug abuse and } \\
\text { homelessness, organizations focusing on } \\
\text { building community cohesion and } \\
\text { empowering disadvantaged individuals }\end{array}$ \\
\hline
\end{tabular}

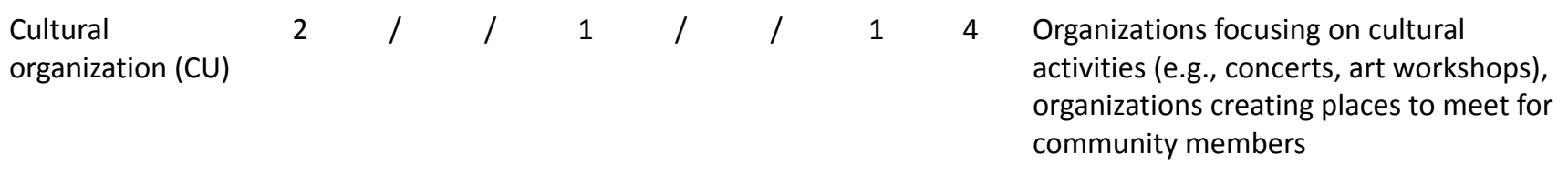

\begin{tabular}{|c|c|c|c|c|c|c|c|c|c|}
\hline $\begin{array}{l}\text { Health } \\
\text { Organization (HE) }\end{array}$ & 1 & 1 & / & / & / & / & / & 2 & Local health centers \\
\hline $\begin{array}{l}\text { Youth } \\
\text { Organization (YO) }\end{array}$ & 1 & 3 & / & / & 1 & / & / & 5 & $\begin{array}{l}\text { Outreach organizations for youth, } \\
\text { organizations focusing on providing } \\
\text { leisure opportunities for children, } \\
\text { day-care organizations, juvenile } \\
\text { delinquency prevention organizations }\end{array}$ \\
\hline
\end{tabular}

$\begin{array}{lllllllll}\text { Total } & 9 & 10 & 8 & 6 & 4 & 4 & 11 & 52\end{array}$

Notes: PC stands for program communities (with CSDP), CC stands control communities (without CSDP). The persons that were interviewed in these organizations were the persons most knowledgeable within the organization with regard to the CSDP.

ified by one fellow researcher. To check the validity of the preliminary findings, the analyses were presented to the study participants and checked if they were in line with their perception of reality (Creswell, 2013). In the findings-section organizations are referred to by the abbreviations used in Table 1.

\section{Findings}

A previous study showed that the CSDP was successful in stimulating sport participation in disadvantaged communities (Marlier et al., 2014). The findings of this present study focus on how the CSDP was able to achieve these results. The capacity building principles are used as a theoretical framework to structure the main findings. When using quotations, we refer to the organizations with the abbreviations used in Table 1.

\subsection{Valuing Pre-Existing Capacities}

This capacity building principle refers to the identification and leveraging of skills, resources and partnerships within the community. Analyses of the interviews indicated that the CSDP leveraged pre-existing capacities by connecting the capacities of sport organizations with the capacities of health, social, youth, and cultural organizations. One manager of a local sport authority, who oper- ated in both the program and control communities, indicated that: "There is definitely a difference between promoting sport in communities with or without CSDP. Staff of the CSDP know their community and their partners and can therefore promote sport activities much better" (SP 1, CC 1).

It became apparent that the CSDP connected information, skills, and resources between the sport sector on the one hand and the youth, health, social, and cultural sectors on the other hand. One manager of a public center for social welfare stated: "I think the role of the CSDP is extremely important. If they did not exist, we would not have a connection between those who don't do sport, the social aspect of sport and competitive sport" (SO 2, PC 1). This connection enabled the CSDP and sport organizations to better reach people in disadvantaged situations: "We notice that, the more we collaborate with partners, the more referrals we get of people in disadvantaged situations. Also, it gives us better insight into their experienced thresholds to do sport" (CSDP, PC 1). Reciprocally, this connection enabled the social, health, and cultural organizations to improve access to sport-specific infrastructure, information, and skills.

Because being able to connect the capacities of different organizations is one of the most essential elements (if not the most essential one) to understand why sport participation was higher in program communities than 
in control communities, we visualized these connections in Figure 1. The figure is based on the analysis of the interviews and is not the result of structural analysis of the network. The arrows represent the connections of the different organizations. Dotted lines symbolize a moderate connection between different organizations (e.g., in both program and control communities, information was exchanged about activities between youth and sport organizations). The full lines in the figure symbolize strong connections between different organizations. These connections represent the organization of mutual activities, sharing of resources, skills and information. In both program and control communities, health, social, cultural, and youth organizations were strongly connected. However, only in program communities, the CSDP acted as a liaison to connect the information, resources, and skills between sport and other organizations in the community. When checking the preliminary findings with the interviewees, they verified that this image was overall an accurate representation of the connections in the community.

\subsection{Developing Trust through a Participatory Approach}

This capacity building principle concerns the capability to involve the target group in the decision-making process of the activities. The analysis of the interviews indicated three factors that helped to induce this participatory approach in sport activities.

A first important evolution to develop more trust through participation was a change of the mix of competences of the staff members. A first shift from a sportfocused to a mix of sport and social profiles helped to increase participation and trust of people in disadvantaged situations. In general, social workers were acknowledged as reinforcing agents due to their affinity with people in disadvantaged situations. A second shift was to recruit disadvantaged individuals as new staff members in the
CSDP, or as new trainers in sport organizations. One sport organization specified: "Over time we made sure we had different trainers from different ethnicities. This really lowered the threshold for ethnic children and adults to go to our sport club" (SP 2, PC 4). Several interviewees indicated that sport activities were much more effective when given by people of the community who had a disadvantaged background, compared to sport activities that were merely offered for them. In some cases, these individuals grew to be the needed community champions, that catalyzed sport participation in their community. One quote of such a community champion illustrates this finding:

After I started working for the CSDP, we talked about my grassroot sport club. A couple of people of the CSDP saw the potential and endorsed my club for funding of the 'city diversity fund.' This allowed my club to expand and organize more activities to reach the target group. Now we developed into a club with as many as 600 members in different sports as Thai boxing, volleyball, indoor football, karate and kickboxing. (SP 1, PC 1)

A second way that illustrates the participatory approach in which staff members of the CSDP operated was to visit the homes, local bars, and other places where disadvantaged individuals would get together. After personal contact and some 'small talk, an initial form of trust was developed. This trust helped to detect the real sportingneeds in the community.

A third way to grow trust through participation was co-organizing low threshold movement opportunities in the 'safe' facilities of partners. Initiating sport sessions in the known and trusted structure of the social or health organizations aided to lower participation thresholds and reach people that otherwise would not have been reached. One quote to illustrate this finding:
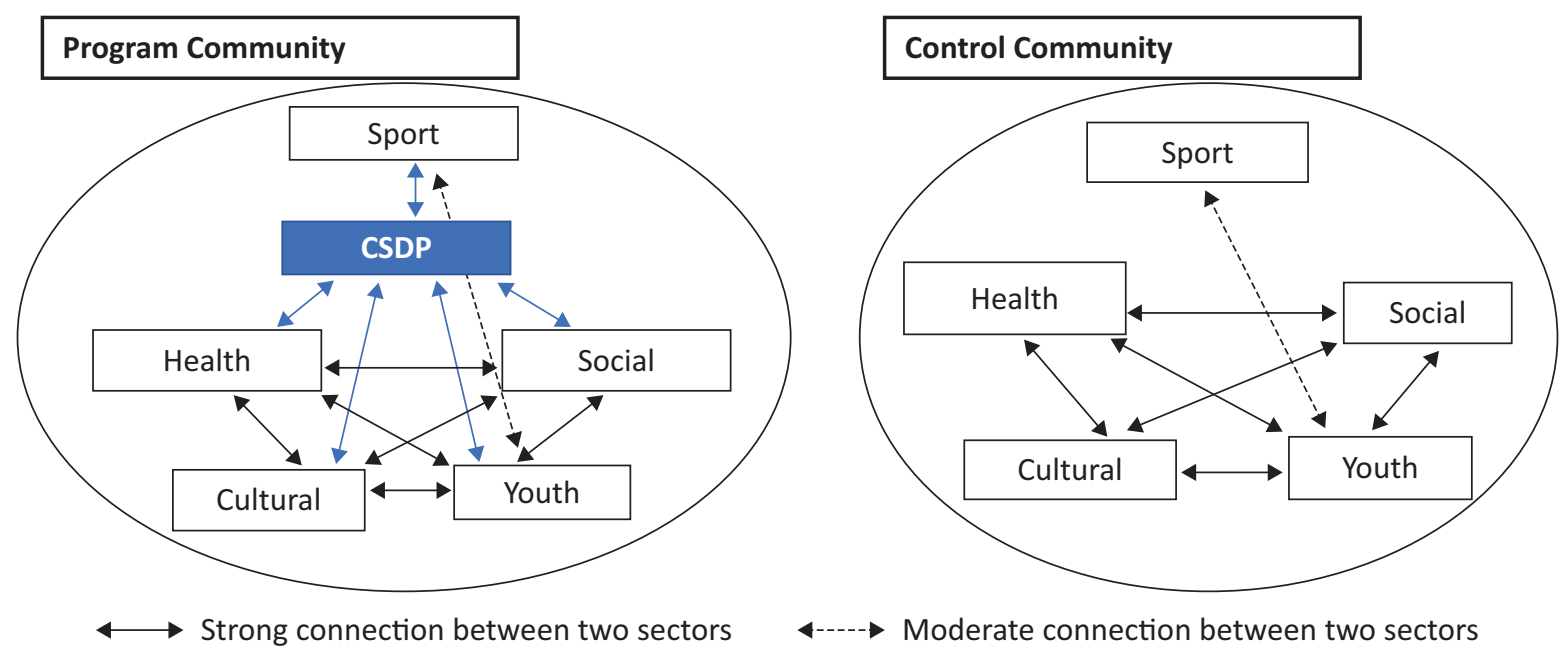

Figure 1. Graphical representation of the connections between sport, health, social, cultural and youth organizations in CSDP and control communities. 
Even if there is a yoga offer in the community, in most cases it takes more to engage them [disadvantaged individual] into these activities. When we organize a yoga course with the CSDP in our infrastructure we reach much more people. (HE 1, PC 1)

\subsection{Being Responsive to Context}

This capacity building principle refers to the ability to adapt to each context. CSDP-staff members specified they have a general framework (see the five key responsibilities and activities in Section 2.1) but can prioritize according to the needs of the community members and organizations.

One element that helped to make activities fitting the needs of their community was that CSDP-staff members are encouraged to experiment and try new activities and methods in their community: "We really are stimulated to innovate....A lot of elements which are now structurally embedded come from former trial and error experiments" (CSDP, PC 2).

Another element of being responsive to context is being able to face challenges due to changes in the physical, economic, cultural and political environment. One interesting finding that emerged from the analysis was how the CSDP tackled new financial, organizational, and cultural pressures in sport clubs that dealt with more disadvantaged members:

At a certain point $70 \%$ of the members of a club were guided through the CSDP and were disadvantaged. This also meant that there were problems getting the membership fee, there was little consumption by this group in the canteen, troubles with transport to the games. Without support [from the CSDP] this club would never be able to sustain themselves. (SP 3, city level)

To respond to these evolutions, the CSDP put several coping mechanisms in place to help sport clubs to manage these new financial, organizational, and cultural pressures.

Financial pressures of those sport clubs were tackled by installing three measures. First, the CSDP would pay the membership fee of people in disadvantaged situations directly to the sport club, so the sport club would not need to worry about getting the payment. One interviewee of a sport organization stated: "Without the financial assistance of the CSDP we would not be able to survive. There are currently 40 members that do not or cannot pay their membership fee" (SP 2, PC 4). Second, the CSDP would install a personalized payment plan for people in disadvantaged situations, so they could spread the payment of the membership fee over different months, which would alleviate the financial threshold. Third, the CSDP aided in recruiting additional resources for the sport clubs by helping to apply for external funding.
Organizational pressures were in part overcome by decreasing the administrative burden. In several sport clubs that were open to engaging with hard to reach groups, professional assistance was offered in dealing with the administration of enrolling new members. This allowed the sport clubs to focus on what they wanted to focus on: sport. Furthermore, interviews with sport club staff revealed that, by partnering with the CSDP, they were able to attract more members and volunteers. Attracting members and volunteers represents a big organizational pressure for many sport clubs.

Cultural pressures were dealt with by informing, explaining, and supporting trainers and board members, on the specific thresholds of different groups of disadvantaged individuals. Such pressures arose when new participants from a different culture, religion, or background joined the sport activities. Additionally, the CSDP helped in explaining the sport clubs' formal and informal norms to people in disadvantaged situations.

\subsection{Developing Well-Planned and Integrated Strategies with Clear Purposes}

This capacity building principle refers to having clear definition of goals, strategies, evaluation, and responsibilities for the different activities.

Interviews with youth, social, cultural, and health organizations made apparent that the value of the CSDP resides in the organization of a multitude of activities and strategies. Table 2 presents an overview of the stakeholders' perceived added value of a couple of activities organized by the CSDP. The added value for the sport organizations is not repeated in the table as it is mentioned in the previous sections. This list is not exhaustive, and although the added value of these activities transcended stakeholder groups, it does give a good overview of the well-planned and integrated strategies of the CSDP.

One important strategy was to reinforce local organizations that already used sport to reach their goals (e.g., guiding activity to sport clubs, consultation service in social and health organizations to inform the target group of local sport opportunities).

Another strategy was to deliver a complementary sport offer when no other organizations in the community could fulfil sporting needs indicated by the individuals in disadvantaged situations (e.g., the bike school, sport activities for women only, mixed culture sport camps).

\section{Discussion}

The purpose of this study was to get better insights in how (sport) organizations can attain higher levels of sport participation in disadvantaged communities. The case for this study was a CSDP in Flanders that was successful in engaging disadvantaged individuals in sport participation (Marlier et al., 2014). The principles of capacity building-i.e., (1) valuing pre-existing capacities, 
Table 2. Indicated added value of activities of the CSDP for social, health, cultural and youth organizations.

\begin{tabular}{lll}
\hline Sector & Activities of CSDP & Indicated added value \\
\hline Social & Bike school & "The bike school for us is part of a course on mobility \\
& that mainly focuses on adult women that are not able
\end{tabular}

Supporting sport activities of partners

The CSDP supports activities of partners by providing trainers with the right sport technical and pedagogical qualifications.

Health Consultation service

Doctors prescribe movement and sport as a medicine and refer them to a CSDP staff member. This staff member explains the opportunities to be physically active in the community (e.g., who to contact, when and where activities take place, the price and how they could get financial support at fixed moments in the building of the health organization.

Cultural Sport and culture camps

The CSDP organizes camps together with culture and youth organizations. In the morning children in disadvantaged situations get sport activities, in the afternoon they get cultural activities.

Youth

Sports Infrastructure

The CSDP provides sports infrastructure that gives priority to people in disadvantaged situations.
"I would need to partake in many extra trainings on the sport technical aspect without the partnership of the CSDP. And I think that the CSDP would miss a whole lot of tools and knowhow to reach the hard-to-reach groups that we are able to reach" (SO 1, PC 4).

"In our center, health prevention is important, but for us, nurses and doctors, it is difficult to get people active....The fact that he [CSDP-staff member] comes to our organization diminishes that threshold and relieves us, because for every sport related question we can refer directly to them" (HE 1, PC 2).

"They [CSDP-staff] really want to engage the community. They invest a lot of time to go to the different organizations, to people in disadvantaged situation to build a week that is adapted to the needs of this group. They organize a lot of games and sports in a professional way, that we would not be able to give with our [cultural] background.... In this way the children get a broader array of leisure time activities which make it more likely for them to find something they like and want to continue doing" (CU 2, PC 1).

"We have a partnership regarding a girl soccer project....The CSDP provides infrastructure and assists in finances. We mainly focus on reaching the target group. So yes, we really reinforce each other targets" (YO 2, PC 2).
(2) developing trust through a participatory approach, (3) being responsive to context, and (4) developing wellplanned and integrated strategies - served as a guiding framework to explain how the CSDPs reached these results. In the next section, we will discuss four key implications for (sport) organizations that want to include individuals in disadvantaged situations.
A first key implication is to link capacities of sport organizations with the capacities of the social, youth, health, and cultural organizations. In this study, the CSDP was able to bridge the gap between sport and non-sport organizations and link their capacities. This resulted in a twofold effect. On the one hand, sport organizations could make use of the expertise and net- 
work of youth, social, and health organizations to reach people in disadvantaged situations. On the other hand, these non-sport organizations could make use of sportspecific skills and the sport infrastructure of sport organizations. Previous studies have demonstrated that reaching this target group represents a capacity deficit for many organizations in the sport sector (Armour \& Sandford, 2013; Theeboom et al., 2010). This deficit has been related to the habit of sport organizations to work in isolation from other organizations (Barnes et al., 2007; Lawson, 2005). In line with these findings, we noted that sport organizations worked largely independent from social, health, and cultural organization in control communities (without CSDP). Other researchers have expressed the importance of leveraging local partnerships and to value pre-existing capacities to include people in disadvantaged situations in sport participation (Hawe, Noort, King, \& Jordens, 1997; Welty Peachey et al., 2018). Svensson et al. (2017) also noted that external partnerships were crucial to overcome capacity deficiencies. In a different study, he recommended that many sport organizations with developmental goals would benefit from additional training and support in building partnerships (Svensson, Andersson, \& Faulk, 2018). This finding confirms the importance of having a coordinated program in a community that can facilitate collaboration between sport and other sectors (Dobbels, Voets, Marlier, De Waegeneer, \& Willem, 2018). In our study, the CSDP executed this coordination function and facilitated collaborations between the different organizations.

The second key implication is to shift from a sportoriented staff to a mix of sport staff, social workers and representatives of people in disadvantaged situations. Our findings showed that staff constitution was an important element to develop trust through a participatory approach. Many authors have stated that an active involvement and participatory approach of individuals in disadvantaged situations is an essential element of each program that aims to have a positive effect for this group (Haudenhuyse et al., 2012; Spaaij et al., 2018). In our study, a mixed staff of social and sport profiles helped to increase affinity with perceived thresholds of people in disadvantaged situations and to engage them in the sport offer. Previous studies affirm that social workers have a more successful understanding of including disadvantaged target groups (Armour \& Sandford, 2013). Interestingly, we found that a new phase of active participation of the target group was established by recruiting trainers and staff with a disadvantaged background. This reaffirms the conclusions of a study on recruiting Muslim women in community sport regarding the crucial character of integrating ethnic minorities in the center of decision-making processes (Maxwell \& Taylor, 2010).

The third key implication is to assist sport clubs to deal with financial, organizational, and cultural pressures that arise from the influx of new members in disadvantaged situations. In line with findings of Coalter (2007), we found that the identification of hard-to-reach groups and guiding them to sport clubs led to new financial, organizational, and cultural pressures. One of the biggest successes of the CSDP was to find a response for these pressures, by (1) taking care of part of the administration, (2) advancing the membership fee, and (3) installing workshops on dealing with cultural differences. By transferring this knowledge to the sport clubs, they were better prepared to be inclusive for these individuals. As such, a safer environment and a positive feedback loop were created, while more peers were attracted. Likewise, Forde, Lee, Mills, and Frisby (2015) concluded that difficult target groups can be integrated in the existing sport offer as long as sufficient efforts are made to reduce potential barriers.

The fourth and final key implication is to reinforce sport activities of partners and deliver a complementary offer only when existing local organizations are not able to fill sporting needs of people in disadvantaged situations. Our findings revealed that the CSDPs were successful in developing well-planned and integrated strategies mainly by reinforcing local organizations that already used sport to reach their goals. Similarly, Vos, Vandermeerschen, and Scheerder (2016) explained that local authorities should only offer sport activities when private and non-profit supply of sport activities is insufficient. The CSDP in this study engaged in many wellplanned and integrated strategies. However, Svensson and Hambrick (2016) argued that picking and choosing battles is important for organizations to be sustainable. Whether or not an organization can integrate this capacity building element will thus largely depend on its stage of development (Svensson et al., 2018; Welty Peachey et al., 2018). It is good to be reminded that this specific CSDP consists of 33 staff members and has been evolving for more than 15 years, which is substantial in comparison with many other CSDPs.

\section{Limitations}

The generalizability of the findings represents the main limitation of this study. More precisely, this study looked at a CSDP in the specific context of disadvantaged communities in one specific city in a Western setting. It is very likely that the implementation of the same program in different communities in different cities could result in distinct outcomes. These outcomes depend largely on the characteristics of the people living in the community, the sport and recreational infrastructure, and the experience of the key stakeholders with community development and partnerships (Trickett et al., 2011). As such, we acknowledge the importance of context when it comes to the effectiveness of the program. In effect, this is the third guiding principle of capacity building theory (NSW Health Department, 2001). We tried to mitigate this limitation by implementing a multiple case that incorporated the views of multiple stakeholders of different sectors. A multiple case design is generally believed to be a stronger base for theory building and generalization 
of the findings (Eisenhardt \& Graebner, 2007; Yin, 2013). However, more work is needed to confirm our findings.

\section{Conclusion}

While capacity building is widely known to engage people in disadvantaged situations, few studies have studied the principles underpinning capacity building theory. Our study applied these principles to enhance our understanding about how organizations can include people in disadvantaged situations in sport.

The capacity building principles were deemed very useful for this purpose. This study differentiates from other work done in this area because it examines a CSDP that was found successful in attaining higher sport participation in disadvantaged communities. Authors in the research field have advocated research on such programs with proven outcomes to advance the understanding of the delivery of sport for individuals in disadvantaged situations (Coalter, 2007; Haudenhuyse et al., 2012).

Our study contributes to practice by formulating four key implications that help to understand how (sport) organizations can include people living in disadvantaged communities. A first key implication is that sport organizations and non-sport organizations should strive to link their capacities. However, as the title of the manuscript gives away, troubled water stands between these two types of organizations before they can value their capacities. In this case study, the CSDP could bridge 'the troubled water' by three actions based on the capacity building principles: (1) shifting staff constitution from a sport-oriented staff to a mix of sport staff, social workers, and representatives of people in disadvantaged situations, (2) helping sport clubs to cope with financial, organizational, and cultural pressures that arise from the influx of new members in disadvantaged situations, and (3) reinforcing sport activities of partners and organizing a complementary offer when existing local organizations are not able to fill sporting needs of people in disadvantaged situations.

\section{Acknowledgments}

The authors of the research would like to thank the staff of the CSDP for their assistance and kind cooperation, the researchers who aided in gathering the data and transcribing the interviews, the board of practitioners who assisted in building the design of the study and helped to filter useful and interesting information for the practitioners on the field, and all interviewees for sharing their time and expertise in helping to understand the success of the CSDP. A sincere thank you goes out to the reviewers who shared their insights and helped to improve the article. Last but not least, the researchers are grateful for the funding provided by the Flemish Policy Research Centre on Sports.

\section{Conflict of Interests}

The authors declare no conflict of interests.

\section{References}

Allison, M. (2001). Sports clubs in Scotland. Edinburgh: SportScotland.

Armour, K., \& Sandford, R. (2013). Positive youth development through an outdoor physical activity programme: Evidence from a four-year evaluation. Educational Review, 65(1), 85-108.

Barnes, M., Cousens, L., \& MacLean, J. (2007). From silos to synergies: A network perspective of the Canadian sport system. International Journal of Sport Management and Marketing, 2(5), 555-571.

Bogaerts, M. (2013). Buurtsport Antwerpen, presentatie bedrijfsbezoek sportmanagement UGent [Community sport development program Antwerp, presentation company visit]. Location: Antwerp.

Cas, J. (Ed.). (2005). Buurtsport scoort: Voortgangsrapport 2005 [The community sport development program scores: Progress report 2005]. Antwerp: Stad Antwerpen.

Coalter, F. (2007). Sport clubs, social capital and social regeneration: Ill-defined interventions with difficult to follow outcomes? Sport in Society, 10(4), 537-559.

Coalter, F. (2010). The politics of sport-for-development: Limited focus programmes and broad gauge problems? International Review for the Sociology of Sport, 45(3), 295-314.

Council of Europe. (2001). Recommendation no. $R$ (92) 13 Rev: Of the committee of ministers to member states on the revised European sports charter. Strasbourg: Council of Europe. Retrieved from https://rm. coe.int/16804c9dbb

Creswell, J. W. (2013). Research design: Qualitative, quantitative, and mixed methods approaches. Thousand Oaks, CA: Sage Publication.

Dobbels, L., Voets, J., Marlier, M., De Waegeneer, E., \& Willem, A. (2018). Why network structure and coordination matter: A social network analysis of sport for disadvantaged people. International Review for the Sociology of Sport, 53(5). https://doi.org/10.1177/ 1012690216666273

Edwards, A., \& Skinner, J. (2010). Qualitative research in sport management. Oxford: Routledge.

Edwards, M. B. (2015). The role of sport in community capacity building: An examination of sport for development research and practice. Sport Management Review, 18(1), 6-19.

Eisenhardt, K. M., \& Graebner, M. E. (2007). Theory building from cases: Opportunities and challenges. Academy of Management Journal, 50(1), 25-32.

Forde, S. D., Lee, D. S., Mills, C., \& Frisby, W. (2015). Moving towards social inclusion: Manager and staff perspectives on an award winning community sport and 
recreation program for immigrants. Sport Management Review, 18(1), 126-138.

Haudenhuyse, R., Theeboom, M., \& Nols, Z. (2012). Sports-based interventions for socially vulnerable youth: Towards well-defined interventions with easyto-follow outcomes? International Review for the Sociology of Sport, 48(4). https://doi.org/10.1177/ 1012690212448002

Hawe, P., Noort, M., King, L., \& Jordens, C. (1997). Multiplying health gains: The critical role of capacitybuilding within health promotion programs. Health Policy, 39(1), 29-42. https://doi.org/10.1016/s01688510(96)00847-0

Heward, S., Hutchins, C., \& Keleher, H. (2007). Organizational change: Key to capacity building and effective health promotion. Health Promotion International, 22(2), 170-178.

Hylton, K., Bramham, P., Jackson, D., \& Nesti, M. (2013). Sports development. London: Routledge.

Jones, G. J., Edwards, M. B., Bocarro, J. N., Bunds, K. S., \& Smith, J. W. (2017). Leveraging community sport organizations to promote community capacity: Strategic outcomes, challenges, and theoretical considerations. Sport Management Review, 21(3), 279-292.

Jones, G. J., Edwards, M. B., Bocarro, J. N., Svensson, P. G., \& Misener, K. (2019). A community capacity building approach to sport-based youth development. Sport Management Review. Advance online publication. https://doi.org/10.1016/j.smr.2019.09.001

Lawson, H. A. (2005). Empowering people, facilitating community development, and contributing to sustainable development: The social work of sport, exercise, and physical education programs. Sport Education and Society, 10(1), 135-160. https://doi.org/ 10.1080/1357332052000308800

Marlier, M., Cardon, G., De Bourdeaudhuij, I., \& Willem, A. (2014). A capacity building approach to increase sports participation in disadvantaged urban communities: A multilevel analysis. Journal of Urban Health, 91(6), 1114-1128.

Marlier, M., Van Dyck, D., Cardon, G., De Bourdeaudhuij, I., Babiak, K., \& Willem, A. (2015). Interrelation of sport participation, physical activity, social capital and mental health in disadvantaged communities: A SEM-analysis. PLoS ONE, 10(10). https://doi.org/ 10.1371/journal.pone.0140196

Maxwell, H., \& Taylor, T. (2010). A culture of trust: Engaging Muslim women in community sport organizations. European Sport Management Quarterly, 10(4), 465-483.

Millar, P., \& Doherty, A. (2016). Capacity building in nonprofit sport organizations: Development of a process model. Sport Management Review, 19(4), 365-377.

Misener, K. E., \& Doherty, A. (2012). Connecting the community through sport club partnerships. International Journal of Sport Policy and Politics, 4(2), 243-255.

NSW Health Department. (2001). A framework for build- ing capacity to improve health. Gladesville: Better Health Care Centre.

Pawson, R., Greenhalgh, T., Harvey, G., \& Walshe, K. (2005). Realist review: A new method of systematic review designed for complex policy interventions. Journal of Health Services Research \& Policy, 10(Suppl. 1), 21-34.

Putnam, R. D. (2007). E pluribus unum: Diversity and community in the twenty-first century the 2006 Johan Skytte Prize Lecture. Scandinavian Political Studies, 30(2), 137-174.

Scheerder, J., Vandermeerschen, H., \& Breedveld, K. (2017). Diversity in participation reigns, policy challenges ahead: Sport for all (ages) from a European perspective. In R. A. Dionigi \& M. Gard (Ed.), Sport and physical activity across the lifespan: Critical perspectives (pp. 45-65). London: Palgrave Macmillan. https://doi.org/10.1057/978-1-137-48562-5_3

Schulenkorf, N., Sherry, E., \& Rowe, K. (2016). Sport for development: An integrated literature review. Journal of Sport Management, 30(1), 22-39.

Simmons, A., Reynolds, R. C., \& Swinburn, B. (2011). Defining community capacity building: Is it possible? Preventive Medicine, 52(3/4), 193-199. https://doi. org/10.1015/j.ypmed.2011.02.003

Skinner, J., \& Zakus, D. H. (2008). Development through sport: Building social capital in disadvantaged communities. Sport Management Review, 11, 253-275.

Spaaij, R., Schulenkorf, N., Jeanes, R., \& Oxford, S. (2018). Participatory research in sport-for-development: Complexities, experiences and (missed) opportunities. Sport Management Review, 21(1), 25-37.

Sport England. (2006). Understanding the success factors in sport action zones. London: Sport England. Retrieved from https://www.sportengland.org/ media/39032/sport-action-zones-evaluation-finalreport.pdf

Svensson, P. G., \& Hambrick, M. E. (2016). "Pick and choose our battles": Understanding organizational capacity in a sport for development and peace organization. Sport Management Review, 19(2), 120-132.

Svensson, P. G., Andersson, F. O., \& Faulk, L. (2018). A quantitative assessment of organizational capacity and organizational life stages in sport for development and peace. Journal of Sport Management, 32(3), 295-313.

Svensson, P. G., Hancock, M. G., \& Hums, M. A. (2017). Elements of capacity in youth development nonprofits: An exploratory study of urban sport for development and peace organizations. Voluntas: International Journal of Voluntary and Nonprofit Organizations, 28(5), 2053-2080.

Theeboom, M., \& De Maesschalck, P. (2006). Sporten om de hoek, een brede kijk op buurtsport in Vlaanderen [Sport around the corner, a broad view on community sport development programs in Flanders]. SintNiklaas: Flemish Institute for Sports Management and Recreation Policy. 
Theeboom, M., Haudenhuyse, R., \& De Knop, P. (2010). Community sports development for socially deprived groups: A wider role for the commercial sports sector? A look at the Flemish situation. Sport in Society, 13(9), 1392-1410.

Trickett, E. J., Beehler, S., Deutsch, C., Green, L. W., Hawe, P., McLeroy, K., ... Schulz, A. J. (2011). Advancing the science of community-level interventions. Journal Information, 101(8), 1410-1419.

Vail, S. E. (2007). Community development and sport participation. Journal of Sport Management, 21(4), 571-596.

Vandermeerschen, H., \& Scheerder, J. (2017). Sport managers' perspectives on poverty and sport: The role of local sport authorities. Sport Management Review, 20(5), 510-521. https://doi.org/10.1016/j.smr.2017. 02.002

Vandermeerschen, H., Vos, S., \& Scheerder, J. (2013).
Who's joining the club? Participation of socially vulnerable children and adolescents in club-organised sports. Sport, Education and Society, 20(8), 941-958. https://doi.org/10.1080/13573322.2013.856293

Vos, S., Vandermeerschen, H., \& Scheerder, J. (2016). Balancing between coordination, cooperation and competition? A mixed-method approach for assessing the role ambiguity of local sports authorities. International Journal of Sport Policy and Politics, 8(3), 403-419.

Welty Peachey, J., Cohen, A., Shin, N., \& Fusaro, B. (2018). Challenges and strategies of building and sustaining inter-organizational partnerships in sport for development and peace. Sport Management Review, 21(2), 160-175.

Yin, R. K. (2013). Case study research: Design and methods. Thousand Oaks, CA: Sage Publication.

\section{About the Authors}

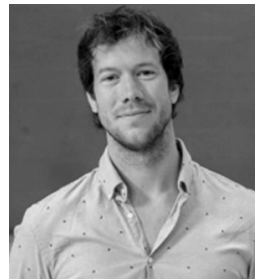

Mathieu Marlier is a Senior Lecturer at the International Sport Management Department at LUNEX University, International University of Health, Exercise, and Sports. His research focuses on the value of cross-sector partnerships in sport. In 2016 he published his PhD in this field while affiliated at Ghent University. Mathieu is currently involved in several European projects regarding social innovation, social inclusion, vital cities, and good governance.

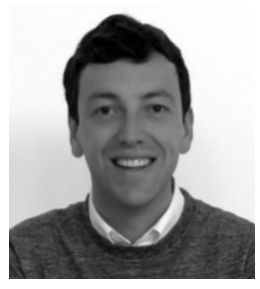

Bram Constandt is a Postdoctoral Researcher at the Department of Movement and Sports Sciences of Ghent University. Holding a PhD in sport management, his current research focuses mainly on how to deal with ethical issues (e.g., match-fixing, gambling, doping) in sport organizations. In addition, he has a strong interest in studying and teaching sport history, thereby highlighting the societal value of sport.

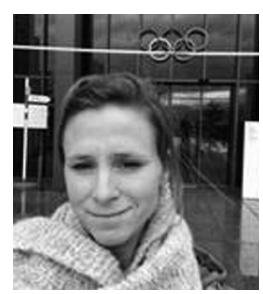

Cleo Schyvinck is a Doctoral Student at Ghent University in the Department of Sport and Movement Sciences. Her research focuses on corporate social responsibility in professional sport organizations.

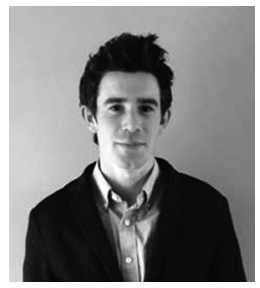

Thomas De Bock is a PhD Candidate at Ghent University, Belgium, in the Department of Movement and Sport Sciences. Thomas started his PhD in 2018 and the main focus of his research is on sport federations' sport-for-all policies. Thomas holds a master's degree in History, EU politics and Business Economics, all three achieved at Ghent University.

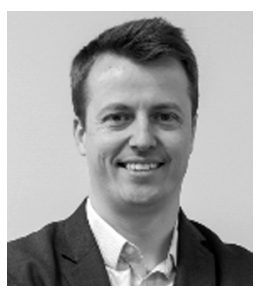

Mathieu Winand is a Professor of Sport Management and Head of Department of International Sport Management at LUNEX International University of Health, Exercise, and Sports in Luxembourg. His research interests are in sport governance, performance management, and innovation in sport. Mathieu is Deputy Editor of Sport, Business and Management and Director of MEMOS in French, the Executive Masters in Sport Organization Management supported by Olympic Solidarity. 


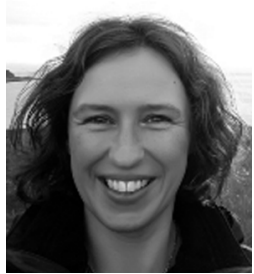

Annick Willem is Associate Professor in Sport Management at the Department of Movement \& Sports Sciences (Ghent University). She is Head of the Sport Management research group. Her research, which appeared in several high-impact academic journals, is on management and policy in the sports sector, with a particular focus on organizational issues such as knowledge management, collaboration, networking, and on ethical management issues. Annick teaches several sport management courses and is academic coordinator of the Belgian Olympic Academy. 